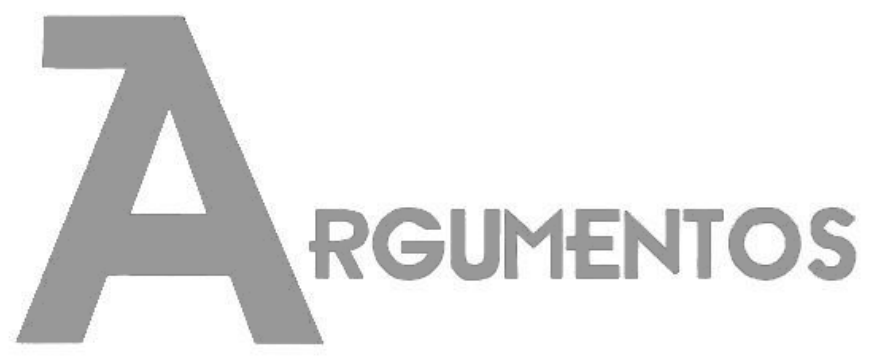

Vol. 16, n. 1, jan./jun. 2019 ISSN: 2527-2551 (online)

\title{
Precariedade e biopolítica: uma leitura do dispositivo de segurança em Michel Foucault ${ }^{1}$
}

Ildenilson Meireles ${ }^{2}$

Recebido em: 09/04/2019

Aprovado em: 09/05/2019

Resumo: O artigo discute o tema da segurança, desenvolvido por Michel Foucault em Segurança, Território, População, com o intuito de mostrar algumas variáveis da própria noção de segurança e o modo como esse dispositivo está diretamente ligado ao processo de precarização da vida. Nossa aposta é que o aproveitamento das tecnologias de segurança no contexto da biopolítica contemporânea cumpre uma função indispensável no interesse das grandes corporações econômicas, a função de precarizar a vida das populações flutuantes no interesse da lógica neoliberal.

Palavras-chave: Segurança. Biopolítica. Foucault. Precariedade.

\section{Precariedad y biopolítica: una lectura del dispositivo de seguridad en Michel Foucault}

Resumen: El artículo discute el tema de la seguridad, desarrollado por Michel Foucault en Seguridad, Territorio, Población, con el propósito de mostrar algunas variables de la propia noción de seguridad y el modo en que ese dispositivo está directamente ligado al proceso de precarización de la vida. Nuestra apuesta es que el aprovechamiento de las tecnologías de seguridad en el contexto de la biopolítica contemporánea cumple una función indispensable en el interés de las grandes corporaciones económicas, a saber, la función de precarizar la vida de las poblaciones flotantes en el interés de la lógica neoliberal.

Palabras-clave: Seguridad. Biopolítica. Foucault. Precariedad.

\section{Precarity and biopolitics: a reading of the dispositif of security in Michel Foucault's} work

\footnotetext{
1 Este artigo é resultado de projeto de pesquisa desenvolvido no PPGH/Unimontes, com recursos da Fundação de Apoio à Pesquisa de Minas Gerais (FAPEMIG).

2 Professor de Filosofia, do Programa de Pós-Graduação em História e do Mestrado Profissional em Filosofia da Universidade Estadual de Montes Claros - Montes Claros, Brasil. E-mail:< meirelesildenilson@gmail.com >. ORCID: https://orcid.org/0000-0002-0528-727X.
} 
Abstract: The paper addresses the subject of security, developed by Michel Foucault in Security, Territory, Population, with the intent of showing some variables of the very notion of security and how this dispositif is directly linked to the process of precarization of life. Our bet is that the exploitation of the technologies of security in the context of contemporary biopolitics fulfils an indispensable function in the big economic corporations' interest, that is to say, the function of the precarization of fluctuating populations' lives in the interest of the neoliberal logic.

Keywords: Security. Biopolitics. Foucault, Precarity.

\section{Introdução}

Um tema muito corrente em nossos dias e que ainda não alcançou o seu termo é o da segurança. Articulada à necessidade de garantir proteção ao cidadão, os Estados modernos se atribuíram a tarefa de pensar estratégias de contenção das contingências impostas pelos modos de organização da vida social, ao mesmo tempo em que se atribuíram a tarefa não menos difícil de pensar estratégias no enfrentamento dos elementos incontroláveis e insubmissos do corpo social. A constituição do estado moderno, aliás, só foi possível à custa de um grande disciplinamento dos indivíduos por meio de vários mecanismos punitivos e tecnologias políticas ortopédicas. Toda a análise feita por Michel Foucault em Vigiar e Punir é uma demonstração clara de que a eficácia do poder exercido no regime de soberania se deve tanto aos instrumentos ou tecnologias políticas orquestrados nos rituais punitivos quanto à disciplina pensada ela mesma como uma tecnologia política dos indivíduos.

É certo que muito antes de narrar os rituais políticos da soberania Foucault já havia destacado, em História da Loucura, o modo como se configurou todo um conjunto de tecnologias médicas em proveito do disciplinamento dos loucos e dominação da loucura. Tratava-se, em última instância, no contexto de História da Loucura, de uma profunda demarcação de espaços sociais cujo resultado não era outro senão o confinamento do louco visando à proteção da sociedade. Também o confinamento do louco era, assim como o ritual punitivo do soberano sobre o criminoso, uma medida de segurança. Em linhas gerais, o problema era este: que medida tomar em relaçãoàqueles indivíduos que se excedem no comportamento, que não reconhecem a autoridade do soberano, que se dizem ser reis quando são mendigos? Que medida tomar para que a desrazão e seus subprodutos não façam sucumbir o corpo social? Quando Foucault narra a dispersão dos loucos no renascimento, são considerados, dentre eles, os avaros, delatores, bêbados, desordeiros, devassos, adúlteros, heréticos. Ou seja, o louco ainda 
não conquistou "especificidade", não tem lugar próprio de reclusão, como acontecerá no século XIX. O que se assiste nesse percurso histórico que vai do final da Idade Média ao final do século XIX é a força da prática do internamento para retirar de circulação todo tipo de perigo social, mas que tem como princípio, além de um valor moral: a miséria, a pobreza, o vício, a fraqueza, a vagabundagem, a doença, a preguiça, a loucura, tudo isso como sendo encarnação do mal e que precisa ser suprimido da terra, um valor também econômico na medida em que o grande enclausuramento, ou, o que dá no mesmo, a grande internação tem por objetivo a recuperação dos indivíduos para o trabalho. Esse é o sentido econômico, por exemplo, do Hospital Geral ${ }^{3}$.

A sofisticação dos mecanismos de segurança nos séculos XX e XXI parece-nos uma sofisticação, em mesmo nível, dos problemas sociais "inventados" pelas instituições e pela lógica do capitalismo com o intuito de obterem para si um campo de ingerência política e uma população economicamente disponível à produção e ao lucro. Por um lado, o sucesso do capitalismo está justamente na sua capacidade de constituir "campos de ingerência" fazendo-os funcionar segundo uma mesma lógica e criando, a partir deles, uma expectativa favorável - mas irrealizável em sua totalidade - de melhoramento das condições de vida. Por outro lado, os efeitos desse 'sucesso' mostraram o cinismo dessa expectativa favorável na medida em que não cessaram de aparecer as contradições inevitáveis do capitalismo que ganham 'vida' cada vez mais nos sujeitos precários que não param de circular pelas margens. E foram essas vidas precárias, desprovidas de qualquer possibilidade de expectativa, que se tornaram um importante campo de ingerência das instituições sociais e econômicas. Nesse sentido, aquilo que circulava pelas margens, às vezes aproveitando as migalhas da lógica produção-consumo, avançou para o centro e tudo se tornou rapidamente sem margens. Isso significa, em última instância, que não há centro em relação à margem do capitalismo, nem mesmo quando se trata de uma análise econômica mais rigorosa que leve em conta países que estão "dentro" e países que estão "fora" do capital.

O subdesenvolvimento e a superexploração do trabalho constituem dois elementos imprescindíveis, inclusive a serem produzidos e administrados, no interior do

\footnotetext{
3 "O internamento, esse fato maciço cujos indícios são encontrados em toda a Europa do século XVII, é assunto de "polícia". Polícia, no sentido preciso que a era clássica atribui a esse termo, isto é, conjunto das medidas que tornam o trabal ho ao mesmo tempo possível e necessário para todos aqueles que não poderiam viver sem ele" (FOUCAULT, 1978, p.72).
} 
sistema capitalista de tipo neoliberal ${ }^{4}$. Ou seja, se de um lado há cada vez mais concentração de riqueza à custa da superexploração da força de trabalho em países 'periféricos' e subdesenvolvidos, de outro há uma completa descentralização, uma descida até às margens, dos processos e das técnicas de subtração de toda e qualquer energia acumulada, esteja ela em vias de ser utilizada (explorada) ou ociosa. É esse paradoxo flagrante do capitalismo, que não pode se manter senão à custa da superexploração da forma de trabalho, que parece ser o pano de fundo da análise que Foucault faz de uma sociedade em regime de biopoder.

Orientada desde sua base pelo paradoxo, uma sociedade de biopoder precisa expandir suas tecnologias até onde se situam vidas passíveis de serem administradas, ainda que essas vidas pareçam, de relance, inutilizáveis e sem valor. No entanto, a expansão do biopoder sobre a vida, assim como a expansão do capitalismo sobre a periferia, não pode ter sucesso se não mantiver um nível aceitável de coordenação daquilo que toma para si como alvo. $O$ paradoxo não deve ser um entrave à dinâmica do biopoder - e do capitalismo -, mas seu móbil fundamental. E é a partir disso que arriscamos nossa aposta de que os mecanismos de segurança, no contexto da biopolítica contemporânea, reforçam o paradoxo fundamental que orienta as expectativas de uma sociedade em regime de biopoder e em regime de um capitalismo neoliberal que cuidou para que as margens se confundissem com o centro e, de maneira recíproca, o centro avançasse sobre as margens e tudo se tornasse um grande 'fora', uma exterioridade irredutível à dicotomia dentro/fora a ser administrada politica e economicamente pelas grandes agências financeiras, principalmente. A leitura de Pelbart (2008) nos ajuda, nesse sentido, pela precisão. Segundo ele,

Se antes ainda imaginávamos ter espaços preservados da ingerência direta dos poderes (o corpo, o inconsciente, a subjetividade) e tínhamos a ilusão de preservar em relação a eles alguma autonomia, hoje nossa vida parece integralmente subsumida a tais mecanismos de modulação da existência. Até mesmo o sexo, a linguagem, a comunicação, a vida onírica, mesmo a fé, nada disso preserva já qualquer exterioridade em relação aos mecanismos de controle e monitoramento, se é que alguma vez tal exterioridade fosse

\footnotetext{
${ }^{4}$ Acompanhamos aqui, mesmo que de sobrevoo, a interpretação que nos pa rece mais apropriada para o que temos em vista na discussão sobre os mecanismos de segurança e que é fornecida por DARDOT e LAVAL (2016). Em linhas gerais, o neoliberalismo não é apenas uma ideologia, um tipo de política econômica. É um sistema normativo que ampliou sua influência ao mundo inteiro, estendendo a lógica do capital a todas as relações sociais e a todas as esferas da vida".
} 
cabível. Para resumi-lonuma frase: o poder já não se exerce desde fora, nem de cima, mas como que por dentro, pilotando nossa vitalidade social de cabo a rabo. Não estamos mais às voltas com um poder transcendente, ou mesmo repressivo, trata-se de um poder imanente, produtivo.

O paradoxo de uma sociedade de biopoder, como mostra o V capítulo de História da Sexualidade I, A vontade de saber, se assenta justamente nessa dificuldade que é, por um lado, promover e garantir a vida em geral, numa grande obstinação política pela manutenção da vida biológica em regime de existência imperecível; mas, por outro, abandonar à morte um quantitativo bastante expressivo de cidadãos e cidadãs, numa não menos obstinada tarefa política de esgotamento da vida dos sujeitos pela exploração de suas forças materiais e imateriais, de sua criatividade, bem como pela violência direta sobre seus corpos e pelo abandono.

\section{Biopoder e segurança}

As análises feitas por Foucault no curso Segurança, Território, População, ministrado em 1978, prometem uma espécie de genealogia desse dispositivo importante à sustentação do estado e à consolidação do biopoder, o dispositivo da segurança. Inicialmente, pode-se tomar o problema da segurança como desfecho de um longo processo de acontecimentos aleatórios ocorridos desde o século XVII, principalmente. A segurança, como nós a entendemos, está intimamente ligada à violência, à criminalidade, ao tráfico, à ação policial, daí a necessidade cada vez mais crescente de paliativos para reaver a ordem e a justiça social, mesmo que isso implique a violência de Estado como forma de justificar o restabelecimento da ordem. A intensificação do discurso pela proteção dos direitos humanos, por exemplo, é efeito manifesto disso. Ou seja, a palavra de ordem dos Estados modernos é "legitimidade". É preciso buscar incessantemente, seja no domínio jurídico ao lado da lei, seja no domínio do convencimento popular, uma justificativa plausível para o exercício da violência de Estado sobre o cidadão de modo que seja aceitável como o último esforço, por isso necessário, de contenção da violência.

Eis um movimento de estrangulamento do poder! Como promover a justiça social sem praticar a violência de Estado? Como defender o cidadão, garantir sua segurança, sem eliminar os outros cidadãos que colocam em risco a sociedade? No entanto, nosso 
esforço será caminhar em outro sentido, talvez para além dessa ideia comumente veiculada de segurança que se resume a uma atuação policialesca por parte do Estado no controle e contenção da criminalidade. Foucault nos dá outra orientação teórica acerca do tema da segurança e é a partir dela que pretendemos explorar nossa análise.

Partindo da pergunta “o que se pode entender por 'segurança'?", ele dá um exemplo que considera banal, mas que parece ser suficiente, por ora, para alcançarmos uma compreensão razoável do problema. Considerando três modulações do mesmo exemplo, sua argumentação avança no sentido de mostrar as implicações existentes entre a figura do criminoso, a disciplina e o aproveitamento político de uma nova dimensão da cidade, que aparece no contexto da biopolítica, o fenômeno da população. Diz ele: "seja uma lei penal, simplíssima, na forma de proibição, digamos, 'não matarás, não roubarás', com sua punição, digamos, o enforcamento, ou o desterro, ou a multa" (FOUCAULT, 2008, p.6). Essa primeira modulação, portanto, bastante objetiva, incide diretamente sobre o crime cometido e sobre o criminoso também de forma bastante objetiva e direta.

Segunda modulação, consideremos, arrisca Foucault,

a mesma lei penal, ainda 'não matarás', ainda acompanhada de certo número de punições se for infringida, mas desta vez o conjunto é enquadrado, de um lado, por toda uma série de vigilâncias, controles, olhares, esquadrinhamentos diversos que permitem descobrir, antes mesmo de o ladrão roubar, se ele vai roubar, etc. E, de outro lado, na outra extremidade, a punição não é simplesmente esse momento espetacular, definitivo, do enforcamento, da multa, ou do desterro, mas será uma prática como o encarceramento, impondo ao culpado toda uma série de exercícios, de trabalhos, trabal ho de transformação na forma, simplesmente, do que se chama de técnicas de penitenciárias, trabalho obrigatório, moralização, correção, etc. (FOUCAULT, 2008, p.7).

Impossível não ver nessa segunda modulação do exemplo os sinais da sociedade disciplinar: vigilância, controle, correção. Aqui a estratégia se inverte. Ao invés de esperar que o crime ocorra para que seja aplicada a pena, trata-se de prevenir o crime por meio das técnicas da vigilância, do controle, da moralização sobre os indivíduos em séries distintas, porém articuladas (escola, família, exército). Caso o crime ocorra - e ele ocorrerá... -, a punição será também de outra natureza: o encarceramento, ao invés do enforcamento. 
Por último, terceira modulação,

seja a mesma lei penal, sejam igual mente as punições, seja o mesmo tipo de enquadramento na forma de vigilância, de um lado, e correção, do outro. Mas, desta vez, aplicação dessa lei penal, a organização da prevenção, da punição corretiva, tudo isso vai ser comandado por uma série de questões que vão ser perguntas do seguintegênero, por exemplo: qual é a taxa média da criminalidade desse tipo? (...). (FOUCAULT, 2008, p.7).

Nessa terceira modulação o problema não é mais colocado em termos de casos isolados, ou mesmo de uma série de indivíduos, mas em termos de uma população. É o aparecimento desse fenômeno de massa, próprio da explosão demográfica do século XIX, que mobilizará novas tecnologias de poder e uma nova percepção da ação política, isto é, uma nova racionalidade de Estado a bem da manutenção do status do próprio Estado e um novo modo de administrar algo tão complexo como as multiplicidades. Dado que esse novo fenômeno em questão é o Leitmotiv do Estado moderno, a questão agora é saber qual o custo real de uma punição, isto é, quanto custa para o estado manter a população em segurança, protegida de toda sorte de intempéries. Partindo do exemplo dado, diz Foucault, "o dispositivo de segurança vai, para dizer as coisas de maneira absolutamente global, inserir o fenômeno em questão, a saber, o roubo, numa série de acontecimentos prováveis". (FOUCAULT, 2008 p.9) Ou seja, como dispositivo do biopoder, a segurança de uma população tem necessariamente que calcular, prever, antecipar, conjecturar todas as variáveis de um acontecimento certo, mas ainda não ocorrido, para que se possa, pelo mesmo cálculo, mobilizar estratégias de coerção e de impedimento eficazes no sentido de manter coesa uma população eliminando os riscos à sua manutenção como população viva, sempre pronta a disponibilizar toda a sua energia produzindo e/ou consumindo.

Mas o que significa "proteger uma população"? Protegê-la de que? De quem? Para Foucault, "as reações do poder ante esse fenômeno vão ser inseridas num cálculo que é um cálculo de custo". (FOUCAULT, 2008, p.9) Não se pode esquecer de que a sociedade do biopoder não pode ser dissociada da sociedade capitalista e do modo de organização do Estado moderno. Nesse sentido, como se trata de um custo ao mesmo tempo econômico e político, a divisão binária entre o permitido e o proibido cede lugar a outra lógica: "vai se fixar de um lado uma média considerada ótima e, depois, estabelecer os 
limites do aceitável, além dos quais a coisa não deve ir". (FOUCAULT, 2008, p.9) É claro que aqui já podemos antecipar os efeitos dessa lógica no cinismo com que o Estado e seus órgãos se ocupam dos problemas cotidianos. A serviço de um intervencionismo ostensivo do Estado na vida cotidiana, para justificar a "necessidade" do Estado e sua política de guerra contra insubmissos e detratores, contra a periferia, os institutos de pesquisa e os meios de comunição fornecem todo o tempo números convincentes de índice de violência inaceitável, criminalidade inaceitável, morte inaceitável e, ao mesmo tempo, a contrapartida surpreendente por parte do Estado que pretende consignar os números alarmantes fornecidos pelas estatísticas e partir para a contraofensiva: violência à violência inaceitável, criminalidade à criminalidade inaceitável, morte à morte inaceitável. Aceitável é, para nós, a violência do Estado quando a coisa sai do controle, quando se vai para além dos limites estabelecidos, além da média.

Paradoxalmente, o estado se articula o tempo todo para manter coesa uma população em termos político-econômicos, mas não pode deixar de produzir ao mesmo tempo mecanismos de coerção, de impedimento, de proibição, de interdição e exclusão, correndo o risco de ele mesmo, o Estado, sair do controle, perder o controle e ir além do estabelecido como aceitável. Aliás, é o risco a que o Estado cedeu desde há muito tempo. A situação de "exceção" 5 com que o estado contemporâneo justifica o exercício de sua política de guerra contra as periferias das cidades, contra pessoas em situação de abandono nas ruas, contra usuários de drogas, comunidades negras quilombolas, comunidades indígenas e tantas outras populações minoritárias, tudo isso soa como o mais elaborado programa biopolítico que avança sobre a vida de uns - empurrando-os para fora da cidade -, resguardando e protegendo a vida de outros ${ }^{6}$. Não se pode, ao mesmo tempo, fazer viver e não deixar morrer.

Esse é o paradoxo fundamental do biopoder. Não se pode cumprir a lógica prometida de somente fazer viver. Mas é necessário cumprir com uma parte

\footnotetext{
${ }^{5}$ Desde uma leitura mais aprofundada de G. Agamben (2010) é possível compreender bem o problema do estado de exceção no contexto da biopolítica contemporânea e a partir da sua interpretação avançar sobre a questão do dispositivo de segurança. Outras aproximações também podem ser feitas, no caso específico do Estado brasileiro, a partir de A guerra não declarada na visão de um favelado (TADDEO, 2012).

${ }^{6}$ De acordo com Butler, "diante da violência massiva do Estado, por exemplo, pode parecer uma tolice ou uma extravagância colocara questão, mas pode ser também que, sob determinadas circunstâncias, o a to violento não reci procado exponha mais do que qualquer outro a brutalida de unilateral do Estado" (2016, p.240-250).
} 
considerável da lógica do biopoder, pois o custo-benefício do estado para 'fazer viver' é bastante razoável para que ele possa alargar seus investimentos políticos sobre a população. Ou seja, o custo-benefício que se obtém com a manutenção da vida de uma população, em sentido econômico e politico, vale bem mais do que o custo-benefício que se obtém com repressão à criminalidade. Além disso, as manobras da economia e da política, para lograrem êxito em seus empreendimentos, precisam considerar uma margem significativa de indivíduos (ou pequenas populações) sempre à margem, mas não fora, da lógica do capital. É nesse sentido que a superexploração do trabalho em países subdesenvolvidos demarca o horizonte cada vez mais promissor das desigualdades sociais, malgrado o 'sentimento' de quem é explorado (um indivíduo, uma categoria de trabalhadores, um país...) alcançar certo conforto em fazer parte do processo, algo que é próprio do capitalismo, produzir desejo ainda que irrealizável (de se tornar livre, de se tornar primeiro mundo...). Em larga medida, essa lógica não é outra senão a disposição neoliberal cujo interesse é definido já em suas bases como interesse de classe e que segue avançando como interesse de "grupos econômicos", de "oligarquias políticas", de "corporações empresariais", de "agências financeiras (bancos)". Todas as populações flutuantes no contexto da biopolítica contemporânea, os grupos minoritários, os indivíduos em regime de vida socialmente precária estão numa relação direta com as diversas formas perversas de "gestão da vida" neoliberais. São efeitos diretos e calculados de uma política dominada pela economia ${ }^{7}$. Isso significa, em outros termos, que as vidas socialmente precárias se encontram numa espécie de encruzilhada quando se trata de depender dessa forma atual de Estado para cobrir suas necessidades básicas. De acordo com Butler,

A condição precária designa a condição politicamente induzida na qual certas populações sofrem com redes sociais e econômicas de apoio de ficientes e ficam expostas de forma diferenciada às violações, à violência e à morte. Essas populações estão mais expostas a doenças, pobreza, fome, deslocamentos e violência sem nenhuma proteção. A condição precária também caracteriza a condição politicamente induzida de maximização da precariedade para populações expostas à violência arbitrária do Estado que

\footnotetext{
7 Partindo de outras motivações teóricas, mas analisando exaustiva e lucidamente a nova ordem econômica mundial, principalmente a partir dos anos 1980, a interpretação de SANTOS (1993) nos ajuda a compreender melhor as investidas do capitalismo neoliberal e suas estratégias de domínio planetário, celebradas por seus defensores como o "triunfalismo" do projeto neoliberal, algo que exige dos países latino-americanos uma nova postura de combate e resistência.
} 
com frequência não têm opção a não ser recorrer ao próprio Estado contra o qual precisa de proteção. Em outras palavras, elas recorrem ao Estado em busca de proteção, mas o Estado é precisamente aquilo do que elas precisam ser protegidas. Estar protegido da violência do Estado-Nação é estar exposto à violência exercida pelo Estado-Nação; assim, depender do Estado-Nação para a proteção contra a violência significa precisamente trocar uma violência por outra. (2016, pp.46-7).

A sedução do estado moderno pela lógica do capitalismo neoliberal o faz aproveitar as duas frentes de problemas. De um lado, se empenha em proteger o cidadão, mas privilegiadamente o cidadão economicamente produtivo em dose farta que responde imediatamente às coordenadas da produção e da superexploração, do consumo, da lei e da norma; de outro, produz miséria por toda parte para justificar sua atuação como mediador necessário na solução de questões sociais. Nesse sentido, o Estado não se acanha em acolher, e até propor, medidas paliativas para conter os efeitos abusivos de sua política de guerra contra as populações flutuantes. Não se cansa de precarizar algumas vidas, esgotá-las de maneira ostensiva, vampirizá-las, deixá-las a nu, no limite, anulá-las. Insere, descaradamente em sua agenda de políticas sociais, projetos de contenção da violência urbana, tomada como causa da insegurança, quando, na verdade, a violência urbana não passa de efeito do seu dispositivo de segurança. Ou seja, ele propõe conter o que ele mesmo produz. A justificativa não pode ser outra senão a violência aceitável para garantir a ordem social e conter a violência inaceitável.

No entanto, apesarde toda a atmosfera de 'legitimidade' da violência, não se pode deixar de investir em técnicas de repressão. Disso depende a eficácia do dispositivo de segurança do Estado. Então, segundo Foucault, na óptica do biopoder, é preciso pensar que "no fundo, a economia e a relação econômica entre o custo da repressão e o custo da delinquência é a questão fundamental" (FOUCAULT, 2008, p.12). Ora, é preciso lembrar que aqueles velhos mecanismos disciplinares e jurídicos provenientes da soberania não desaparecem completamente. Ao contrário, eles são, em larga medida, reativados pelo biopoder na medida em que servem de auxílio à manutenção de uma sociedade normalizada e ao processo ininterrupto de normalização da população. Foucault entende que os mecanismos modernos de segurança incluem o conjunto legislativo e as obrigações disciplinares: "leis, depois disciplina, depois segurança. A segurança é uma certa maneira de acrescentar, de fazer funcionar, além dos 
mecanismos propriamente de segurança, as velhas estruturas da lei e da disciplina". (FOUCAULT, 2008, p.14).

\section{A segurança como dispositivo biopolítico}

Se retomarmos aqui as primeiras discussões acerca da noção de biopoder, ou da passagem da sociedade disciplinar para uma sociedade de biopoder, reconheceremos mais facilmente os elementos próprios do dispositivo de segurança. Foucault defende a tese de que há uma evolução dos mecanismos de segurança nas sociedades ocidentais. Isso significa dizer que na sociedade de soberania e na sociedade disciplinar funciona um certo dispositivo de segurança que alcança sua eficácia como "aparelho" de Estado na virada do séc. XVIII para o séc. XIX e aí se instala como algo indispensável à manutenção de um certo registro social. Para Foucault (2008, p.15),

trata-se da emergência de tecnologias de segurança no interior, seja de mecanismos que são propriamente mecanismos de controle social, como no caso da penalidade, seja dos mecanismos que têm por função modificar em algo o destino biológico da espécie.

Essa passagem dá a nota precisa da complexidade e do alcance pretensioso dos mecanismos de segurança. No primeiro caso, são tecnologias muito específicas que procuram responder a demandas socioeconômicas. A penalidade, por exemplo, constitui um mecanismo de controle social na ordem das tecnologias jurídicas de segurança. $\mathrm{O}$ aparelhamento jurídico, portanto, de acordo com essa análise, estaria sob as coordenadas do dístico do bipoder: fazer viver e deixar morrer. Não só a penalidade, as prescrições da lei, as punições efetivas, mas a polícia constitui também um mecanismo de segurança no sentido jurídico na medida em que é preciso garantir os "direitos" da população, do conjunto de cidadãos que cumpre a lei, para protegê-lo das investidas inimigas externas e internas. Assim, não se pode dizer que o problema da segurança se reduza a uma questão de polícia (mais militares nas ruas...). A estrutura é mais complexa ${ }^{8}$. No segundo caso, as tecnologias de segurança tem em vista, além do

\footnotetext{
8 Do mesmo modo, segundo Butler, não se pode reduzir a questão da violência ao Estado nem fazer da violência um elemento unilateral. Mais que um princípio, a não violência surge "como um discurso, um apelo" (2016, p.233). Para demonstrar a complexidade em torno do problema da segurança e evitar um
} 
controle social (assujeitamento, alienação, dominação etc.), o aprimoramento da espécie no sentido propriamente biológico, ou seja, retoma-se com isso o problema da raça, do racismo de Estado que insiste em se camuflar nos discursos democráticos ou dos direitos humanos ${ }^{9}$. Existe hoje, como sabemos, toda uma política em favor do "melhoramento" genético cujo financiamento de pesquisas é em grande parte bancado pelo poder de Estado, pelas grandes corporações multinacionais, pelos grandes laboratórios ${ }^{10}$. Portanto, temos aí um mecanismo que tem por função modificar "algo" na espécie e modificar "em algo" o destino biológico da espécie. As ciências médicas, por exemplo ${ }^{11}$, servem justamente a esse propósito como mecanismo de segurança em relação ao qual é preciso investir todos os esforços políticos e econômicos na medida em que ele pode garantir o sucesso da eficácia do Estado na sua promessa de salvaguardar a vida da espécie. O risco iminente nesse projeto biopolítico de melhoramento genético aparece, por um lado, nas coordenadas socioeconômicas que o conduzem desde o princípio; e, por outro, na grande exclusão reforçada cada vez mais pelas mais variadas formas de racismo que se desdobram no interior do corpo social colocando cidadãos contra cidadãos. E Nietzsche (2000, p.52) já alertava para o cuidado que é preciso ter com os "melhoradores da humanidade"!

Flertando profundamente com o racismo de Estado, encontramos, numa outra ponta, o discurso classista perpetrado pelas democracias neoliberais no encaminhamento das políticas públicas. As cidades de São Paulo e Rio de Janeiro são hoje, no Brasil, os exemplos mais escancarados de um racismo de Estado no que diz respeito a políticas públicas de exclusão, abandono e violência de populações flutuantes. Uma verdadeira guerra de vida e morte, higiene social, limpeza urbana do lixo humano, separatismo confesso coordenado pelo interesse especulativo de bancos, agências imobiliárias, planos de saúde etc., mas não somente, cuja pretensão, mais que ocupar, é se apropriar de todos os espaços da cidade para fins de proveito econômico.

reducionismo, Butler faz uma aposta arriscada em sua análise. Segundo ela, "há formas de violência que estão destinadas a se contrapor ou a deter outras violências: as táticas de defesa pessoal, assim como a violência realizada em nome do combate à atrocidade ou à fome, ou outras crises humanitárias, ou nos esforços revolucionários para instituir uma política democrática" (p.235). Nesse sentido, diz Butler, "minha a posta é que, se há receptividade à reivindicação, então será menos fácil aceitar a violência como um fato social normal" (p.235).

${ }^{9}$ Cf., sobre isso, CORRÊA, 2014.

10 Cf., GADELHA, 2015.

11 Idem. 
Tudo esse movimento de apropriação do espaço publico pelas agências, sempre nos termos da legitimidade, traduz muito claramente a natureza do problema. Trata-se de dominar a política pela economia, em sentido neoliberal, com o objetivo de privatizar a coisa pública mantendo o Estado em funcionamento, principalmente o seu ordenamento jurídico, a bem das grandes agências. Por isso o investimento cada vez mais crescente em tecnologias de segurança, no sentido em que Foucault sinalizou de "securité", ou seguridade, proteção e tutela por parte do Estado.

Numa entrevista a R. Lefort, para a Tribuna Socialista, em 1977, Foucault (2001, p.385) é questionado sobre o sentido do termo securité e fornece uma explicação que dá o contorno essencial da noção, ao mesmo tempo em que mostra um deslocamento importante mobilizado por uma nova exigência social a que estão voltados os mecanismos de segurança, a população. Diz ele,

O que se passa, pois, hoje? A relação de um Estado com a população se dá essencialmente sob a forma daquilo que se poderia chamar o "pacto de seguridade". Antigamente, o Estado podia dizer: "Eu vou Ihes dar um território" ou: "Eu garanto que vocês vão poder viver em paz em suas fronteiras". Isto é o pacto territorial e a garantia das fronteiras era a grande função do Estado. Hoje, o problema fronteiriço dificilmente se coloca. O que o Estado propõe como pacto à população é: "vocês estarão assegurados". Assegurados contra tudo o que pode ser incerteza, acidente, perigo, risco. Vocês estão doentes? Terão a seguridade social! Não têm trabalho? Terão um seguro desemprego! Há um maremoto? Criaremos um fundo de solidariedade! Há delinquentes? Garantiremos sua recuperação, uma boa vigilância policial! ${ }^{12}$

O argumento mais explícito de Foucault acerca da emergência de tecnologias de segurança é que se trata de um problema que não é recente, mas que se torna uma dificuldade para o Estado moderno: como lidar com as multiplicidades? A nosso ver, esse argumento alimenta uma boa expectativa em relação ao modo como as cidades brasileiras lidam com suas questões sociais, isto é, como lidar com as periferias? Do mesmo modo, no caso europeu, como lidar com os refugiados? No caso americano, como lidar com os latinos, negros e muçulmanos? São sempre 'populações flutuantes', multiplicidades que despertam desde sempre a preocupação dos Estados com a segurança da população. Por isso, no nível mais radical do dispositivo da segurança, e é

\footnotetext{
12 A entrevista leva o título Michel Foucault: la sécurité et l'État e está publicada nos Dits et Écris. A tradução da citação é de nossa autoria.
} 
o que faz dela justamente um 'dispositivo' ${ }^{13}$, está o discurso da raça e o problema decorrente do nacionalismo. Não é à toa que todo o ordenamento jurídico é acionado para justificara soberania nacional, em caso de guerra, quando uma nação está sob a ameaça de 'inimigos' externos e de sublevações internas.

\section{Conclusão}

O exemplo que Foucault oferece acerca da formação das cidades francesas ilustra bem os avanços das tecnologias de segurança $e$ isso pode nos servir no encaminhamento da nossa questão. De um lado, um modelo de cidade "essencialmente caracterizada por uma especificidade jurídica e administrativa que a isolava ou a marcava de maneira bastante singular em relação às outras extensões e espaços do território" (FOUCAULT, 2008, p.17). De outro lado, "o crescimento do comércio e da demografia urbana colocava o problema do seu adensamento e do seu encerramento no interior das muralhas" (p.17). Ou seja, na linha histórica que marca os acontecimentos do século XVIII ao século XIX, uma nova configuração daquilo que caracteriza a cidade levanta uma série de problemas que desemboca no problema da segurança: fundamentalmente, o problema da circulação. Circulação de alimentos, circulação de pessoas, circulação de produtos para comércio, mas também "circulação das idéias, circulação das vontades e das ordens, circulação comercial também" (p. 20). Saímos de uma análise do modelo de soberania e parece que estamos retornando a ele. Em que sentido? Esses novos problemas que surgem e que exigem repensar a cidade e as relações sociais no interior dela colocam uma questão fundamental: a questão da centralização dos elementos normativos da cidade. É aí que Foucault toma o projeto de um engenheiro do século XVII, Alexandre Le Maître, para ilustrar a necessidade de constituição de um lugar em que funcionassem as decisões acerca das circula ções, a Capital. É a essa representação que nos remete a ideia de Estado. Um lugar específico do poder. O lugar do rei. Lugar não somente onde as decisões são tomadas, as ordens

\footnotetext{
13 O belíssimo texto de Deleuze (2016), "o que é um dispositivo?", permanece referência essencial acerca do tema, mas também a análise feita por G. Agamben (2005), em texto homônimo, nos parece fundamental, pois o filósofo italiano argumenta a favor da importância decisiva das "questões terminológicas" para a compreensão de uma filosofia. Dispositivo, nesse caso, segundo Agamben, mas também para Deleuze, é algo decisivo no pensamento de Michel Foucault.
} 
expedidas, os decretos assinados, mas o lugar de onde emana o poder do soberano. É nesse sentido que parece que retornamos ao poder soberano, agora de modo mais sofisticado na figura, não de um Rei num território delimitado juridicamente, mas de um Estado politicamente soberano num território aberto juridicamente e solidário a outros.

Mas isso pode nos induzir a erro. No conjunto das análises que Foucault faz em Segurança, Território e População e Nascimento da Biopolítica o desfecho dessa questão não é a mera repetição do modelo de soberania. Trata-se de uma mudança substancial na arte de governar, pois não se trata mais somente do território e das riquezas a serem administrados. A questão do gouvernement posta por Foucault como essencial no interior da sua genealogia do Estado moderno tem como horizonte justamente o fenômeno da população. A arte de governar, portanto, diz respeito à distribuição e maximização das tecnologias capazes de combinar vários elementos - materiais e imateriais - sem os quais seria impossível uma população em regime de administração biopolítica. Nesse sentido, acompanhamos a interpretação de Fonseca (2016, p.113) segundo a qual

Os dispositivos de segurança são mecanismos de produção de liberdades, eles atuam compondo uma situação atual de liberdade calculando no complexo embate entre interesses divergentes como assegurar que um interesse não coloque em risco, ou seja, não represente perigo para o interesse coletivo. A dupla face econômica e política do governo, visível na estreita relação entre liberdade e segurança, se articula, assim, a uma cultura do perigo.

Assim, buscando evitar o perigo maior da desarticulação total das multiplicidades, a reorganização da cidade tem em vista a perfeita administração da população de forma ao mesmo tempo centralizada e descentralizada, oscilação que atende perfeitamente, num regime de economia neoliberal, aos gestores da coisa pública. Centralizada, pois há um alinhamento das várias "agências" no interesse da força de trabalho do cidadão para fins de superexploração da mesma a bem do capital; descentralizada, pois essa tarefa não consiste mais numa aptidão específica de um Estado ou de um governo, mas das agências econômicas, do grande capital proteiforme que se incumbiu de produzir personagens políticas, verdadeiros fantoches, como campo de ingerência da economia. O custo social dessa ingerência, não é preciso ir muito longe, as vidas precárias que circulam pelas ruas de nossas cidades, verdadeiras populações flutuantes, sem lugar, 
sem casa, sem rosto, sem trabalho, sem presente e sem futuro. Mendigos, desempregado/as, gays, aposentado/as, prostitutas, travestis, negro/as, crackeiro/as, crianças, toda uma horda de anormais contemporâneos sobre a qual a política neoliberal se atribuiu a tarefa dupla e paradoxal de "fazer viver", quando possível e lucrativo, e "deixar morrer", quando não houver mais força produtiva a ser explorada. Vidas nuas, vidas nulas, vidas precárias, vidas não passíveis de luto.

\section{Bibliografia}

AGAMBEN, G. O que é um dispositivo? Tradução de Nilcéia Valdati. Outra Travessia, n. 5, 2005, pp.9-16.

BUTLER, J. Quadros de Guerra: quando a vida é passível de luto? Rio de Janeiro: Civilização Brasileira, 2016.

CORRÊA, Murilo Duarte Costa. Biopolítica e direitos humanos: Giorgio Agamben e uma antropolítica evanescente. Profanações, Ano 1, n. 1, p. 22-37, jan./jun. 2014.

DELEUZE, G. O que é um dispositivo. In: Dois Regimes de Loucos. Tradução de Guilherme Ivo. Editora 34, 2016.

DARDOT, P. ; LAVAL, C. A nova razão do mundo. São Paulo: Boitempo, 2016.

FONSECA, Angela Couto Machado. Biopolítica e Direito: fabricação e ordenação do corpo moderno. Belo Horizonte: Arraes Editores, 2016.

FOUCAULT, M. Vigiar e Punir. Petrópolis: Vozes, 2009. . História da Loucura na Idade Clássica. Rio de Janeiro: Perspectiva, 1978. . História da Sexualidade I: A vontade de saber. Rio de Janeiro: Graal, 1988. . Em defesa da sociedade. São Paulo: Martins Fontes, 2005. . Segurança, Território, População. São Paulo: Martins Fontes, 2008.

_. Nascimento da Biopolítica. São Paulo: Martins Fontes, 2008.

_. Dits et Écrits, v.II. Paris: Gallimard, 2001.

GADELHA, Sylvio. Biopolítica, biotecnologias e biomedicina. Revista Subjetividades, Fortaleza, 15(3): 407-416, dezembro., 2015.

PELBART, Peter P. Vida e morte no contexto da dominação biopolítca. In: Revista de Estudos Avançados, s/n, s/d, USP, 2008. 
Artigo | Precariedade e biopolítica: uma leitura do dispositivo de segurança em Michel Foucault (MEIRELES, Idenilson)

SANTOS, Theotônio dos. Economia mundial, integração regional $e$ desenvolvimento sustentável. Petrópolis: Vozes, 1993. 